\section{Comparative study of carboxylate and amide forms of HLDF-6 peptide: Neuroprotective and nootropic effects in animal models of ischemic stroke}

\author{
Anna P Bogachuk ${ }^{1 *}$, Zinaida I Storozheva ${ }^{2}$, Andrey T Proshin ${ }^{3}$, \\ Vyacheslav V Sherstnev ${ }^{3}$, Irina V Smirnova1, Tatyana M \\ Shuvaeva ${ }^{1}$ and Valery M Lipkin ${ }^{1}$
}

'Shemyakin and Ovchinnikov Institute of Bioorganic Chemistry, RAS, Moscow, Russia ${ }^{2}$ Federal Medical Research Centre of Psychiatry and Narcology, Moscow, Russia

${ }^{3}$ Anokhin Institute of Normal Physiology, Moscow, Russia

\section{Abstract}

Aim: The work was to perform a comparative study of the neuroprotective and nootropic activities of two pharmaceutical substances, the HLDF-6 peptide and its amide form (HLDF-6$\mathrm{NH}_{2}$ ).

Materials and Methods: We used in the study healthy adult male Wistar rats aged 180-200 days weighing $280-300 \mathrm{~g}$. We modelled ischemic stroke in rats by chronical occlusion of carotid arteries. Solutions of the HLDF-6-NH ${ }_{2}$ and HLDF-6 peptides were administered intranasally. Cognitive functions we assessed with Novel object recognition test and Morris maze.

Results: The amide form of HLDF- 6 peptide is more efficient: the neuroprotective activity of HLDF-6- $\mathrm{NH}_{2}$, evaluated by improvement of cognitive functions in animals, surpassed that of the native HLDF- 6 peptide. A dose of $250 \mu \mathrm{g} / \mathrm{kg}$ of HLDF-6- $\mathrm{NH}_{2}$ peptide resulted in practically complete restoration of the disturbed functions. In the model of ischemic stroke, the amide form of the peptide significantly excelled the reference substance mexidol both in the effective dose and biological activity.

Conclusion: The results of study of the agent allow hoping for its success in further clinical investigation. In view of high demand for the agent and in case of successful clinical trials, it will surely become widely used in clinical practice in treatment of IS.

\section{More Information}

*Address for Correspondence: Anna P Bogachuk, Laboratory of hormonal regulation, Shemyakin and Ovchinnikov Institute of Bioorganic Chemistry, 16/10 Miklukho-Maklaya Street, Moscow 117997, Russia, Tel: +7 49533651 11; Email: apbogachouk@gmail.com; abog2007@mail.ru

\section{Submitted: 27 March 2019 \\ Approved: 23 July 2019}

Published: 24 July 2019

How to cite this article: Bogachuk AP, Storozheva ZI, Proshin AT, Sherstnev VV, Smirnova IV, et al. Comparative study of carboxylate and amide forms of HLDF-6 peptide: Neuroprotective and nootropic effects in animal models of ischemic stroke. J Neurosci Neurol Disord. 2019: 3: 096-101.

\section{DOI: 10.29328/journal.jnnd.1001022}

Copyright: @ 2019 Bogachuk AP, et al. This is an open access article distributed under the Creative Commons Attribution License, which permits unrestricted use, distribution, and reproduction in any medium, provided the original work is properly cited

Keywords: HLDF: Human Leukemia Differentiation Factor; HLDF-6-OH (H-TGENHR-OH) Peptide and its amide form HLDF-6- $\mathrm{NH}_{2}$ (H-TGENHR$\mathrm{NH}_{2}$ ); Neuroprotective and Nootropic activities; Ischemic stroke

Abbreviations: HLDF: Human Leukemia Differentiation Factor; AD: Alzheimer's Disease; IS: Ischemic Stroke; AF: Amide Form; CF: Carboxylate Form; SPF: Specific Pathogen-Free; PS Pharmaceutical Substance

\section{Check for updates}

\section{Introduction}

Cerebrovascular diseases are among the most urgent medical and social problems of the modern world. The prevalence of nervous system diseases associated with circulatory insufficiency is up to $20 \%$ of the population and is trending upwards. Many nervous system diseases are characterized by a lingering severe course and persistent functional defects resulting in limited or total disability [1]. One of the most severe cerebrovascular diseases is ischaemic stroke (IS). Mechanisms of brain tissue damage development under conditions of cerebral ischaemia necessitate the introduction of a special type of therapy known as neuroprotection. Neuroprotection is aimed at interrupting the delayed mechanisms of cell death-oxidative stress, cytokine imbalance, local inflammation, trophic dysfunction, and apoptosis. A tight interconnection between all mechanisms of nervous tissue death motivates exploitation of the modulating effect that could be achieved through stimulation of the regulatory systems. Peptides are among the key players in regulatory processes [2]. An optimal scenario of therapy for IS and other cerebral disorders should comprise the application of agents simultaneously affecting several key components in the pathogenesis of the disease. Another important requirement for these compounds is the absence of toxic effects when used for prolonged preventive treatment. Due to 
their role as endogenous regulators, peptides can potentially exert multidirectional effects with low toxicity. In recent years, peptide agents have undergone extensive development due to the high selectivity of their effects in addition to theirminimal adverse effects, solubility in aqueous media, low toxicity, lack of immunogenicity, and low molecular weight [3]. Research on human leukaemia differentiation factor (HLDF), which we were the first to discover and isolate [4], revealed a hexapeptide fragment, Thr-Gly-Glu-Asn-His-Arg (HLDF-6), that reproduced the differentiating effects of the full-size factor. Direct evidence of the neuroprotective effects of HLDF6 were obtained from experiments in a primary culture of neuronal cells from the hippocampus and cerebellum as well as in immunocompetent cells [5-8].

In experimental models of clinical pathologies-Alzheimer's disease (AD) and IS-the peptide was demonstrated to alleviate pronounced cognitive deficiency and promote memory retrieval. As demonstrated $[9,10]$ by histological studies of experimental animal brain slices, the damaged area of hippocampal neurons decreased almost three-fold upon intramuscular injection of the peptide. In addition, HLDF- 6 did not modify the haemodynamic indices, nor did it disrupt motion activity or motor coordination in the animals [11]. Have shown that administration of the HLDF- 6 peptide to animals with chronic brain ischaemia provided a reliable neuroprotective effect, protecting brain neurons from death under ischaemic conditions. In the years 2012-2014, we performed a full-scale preclinical study of a highly potent innovative therapeutic agent based on HLDF- 6 that exhibited nootropic and neuroprotective effects. The aim of this study was to develop a pharmaceutical product for the prevention and treatment of neurodegenerative (AD) and cerebrovascular (IS) disorders. In the course of the pharmacokinetics study of two forms of HLDF-6, i.e., the native peptide (HLDF-6-OH) and its amide (HLDF-6- $\mathrm{NH}_{2}$ ), we found that HLDF-6- $\mathrm{NH}_{2}\left(\mathrm{H}-\mathrm{TGENHR}-\mathrm{NH}_{2}\right.$ ) possessed a high hydrolytic ability in blood plasma. The halflife of HLDF-6- $\mathrm{NH}_{2}$ in plasma is $8 \mathrm{~min}$, which is several times higher than the value for the carboxylic form of the peptide (H-TGENHR-OH) (2 min) [12]. Therefore, in the process of preclinical trials, we performed an extensive comparative study of the neuroprotective and nootropic activities of the two pharmaceutical substances (PS)-HLDF-6-OH and HLDF6- $\mathrm{NH}_{2}$ - to find the most efficient form of the HLDF-6 peptide. The investigation was performed in animal models of AD and IS [12]. Reported the results obtained upon the comparative study of neuroprotective and nootropic activities of HLDF6-OH and HLDF-6- $\mathrm{NH}_{2}$ in animal models of AD. In this study, we describe the results of similar investigations in the animal model of ischaemic stroke (IS) - (chronical occlusion of carotid-2-VO) We focused on the study of cognitive functions to identify the most effective form and doses of the drug in order to further study the mechanisms of its action and possible therapeutic potential.

\section{Materials and Methods}

\section{Synthesis of the HLDF-6-OH and HLDF-6- $\mathrm{NH}_{2}$ peptides}

Synthesis of two pharmaceutical substances on the basis of HLDF-6-OH and HLDF-6- $\mathrm{NH}_{2}$ peptides is described in another paper [12].

\section{Experimental animals}

Healthy adult male Wistar rats aged 180-200 days weighing 280-300g were used in this study. Animals were housed according to the current hygienic rules for the arrangement, equipment, and maintenance of experimental biology clinics. The standard laboratory diet was consistent with current norms. Animals were kept four in a cage under conditions of free access to water and food at $21^{\circ} \mathrm{C}$ during a constant 14-h day (with the lights turned on at $8 \mathrm{am}$ ). Environmental factors (temperature, humidity, illumination, and bedding composition) met the requirements for laboratory animal care and use. Control and experimental animals were maintained under the same conditions. The study was performed according to the Rules of Laboratory Practice in the Russian Federation, the recommendations of the Guidance on Preclinical Studies of Drug Substances [13] and the requirements of the international FDA GLP and OECD GLP rules using specific pathogen-free (SPF) laboratory animals (experimental biomodels). The animals were produced at the Animal Breeding Facility (Branch of Shemyakin and Ovchinnikov Institute of Bioorganic Chemistry, Russian Academy of Sciences, Pushchino, Moscow region, Russia). The facility has full AAALAC (Association for Assessment and Accreditation of Laboratory Animal Care International) accreditation. The quality management system in the facility has been certified according to the requirements of the international ISO 9001:2008 standard. All procedures were performed according to approved protocols. Each procedure involving animal treatment was reviewed and approved by the Committee on Humane Animal Treatment prior to the experiment.

\section{IS modelling in rats by chronic occlusion of carotid arteries, a 2 VO model}

Surgery for bilateral ligation (occlusion) of the carotid arteries was performed under general anaesthesia (Zoletil $15 \mathrm{mg} / \mathrm{kg}+$ xylazine $2 \mu \mathrm{g} / \mathrm{kg}$ intraperitoneally). During the surgery, we fixed the animals in a restraining chair and made a longitudinal incision on the frontal surface of the neck. With the help of pincers and glass hooks, the carotid artery was separated from the vagus nerve and ligated with a silk suture. In the sham operated animals, the silk suture underplayed the artery without occlusion as recommended by [14]. Rats were divided into nine groups (10 animals per group) as follows: group 1, sham-operated animals; group 2 (control), animals that were treated intranasally with saline; groups 3-5, animals that were treated intranasally with HLDF-6- $\mathrm{NH}_{2}$ at a dose 
of $250 \mu \mathrm{g} / \mathrm{kg}, 50 \mu \mathrm{g} / \mathrm{kg}$, and $10 \mu \mathrm{g} / \mathrm{kg}$, respectively; groups 6-8, animals that were treated intranasally with HLDF-6-OH at a dose of $250 \mu \mathrm{g} / \mathrm{kg}, 50 \mu \mathrm{g} / \mathrm{kg}$, and $10 \mu \mathrm{g} / \mathrm{kg}$, respectively; group 9, animals that were injected intraperitoneally with a reference drug, mexidol, at a dose of $200 \mathrm{mg} / \mathrm{kg}$. Overall, we operated on 96 animals, and mortality was $6.04 \%$ (6 rats). Two animals died in the control group; 1 animal, in group 6 (HLDF-6-OH at a dose of $250 \mu \mathrm{g} / \mathrm{kg}$ ); 2, in group 7 (HLDF-6$\mathrm{OH}$ at a dose of $50 \mu \mathrm{g} / \mathrm{kg}$ ), and 1, in group 8 (HLDF-6-OH at a dose of $10 \mu \mathrm{g} / \mathrm{kg}$ ). All deaths occurred within 2-24 h after surgery.

\section{Protocols for peptide administration and the assessment of cognitive function}

HLDF-6- $\mathrm{NH}_{2}$ and HLDF-6-OH peptide solutions were administered intranasally at a volume of $48 \mu \mathrm{L} / \mathrm{kg}$ divided between two nostrils. The reference drug, mexidol, was administered at a dose of $200 \mathrm{mg} / \mathrm{kg}$ intraperitoneally in $1 \mathrm{~mL} / \mathrm{kg}$ saline. Administrations were performed 1 and 24 $\mathrm{h}$ after the surgery, as well as on days 3, 5, and 7 after the surgery. Cognitive function was assessed using novel object recognition 14-16 days after the surgery and the Morris maze test18-22 days after the surgery. All behavioural tests were conducted between 11.00 and 15.00 .

\section{Novel object recognition test}

The novel object recognition test was performed under room lighting in a $45 \times 45 \times 40 \mathrm{~cm}$ grey plastic chamber. The test included three 5-min sessions at 24-h intervals as follows: 1 , without objects, for adaptation to the setup; 2 , with two identical objects-metallic cylinders $6 \mathrm{~cm}$ in diameter and 8 $\mathrm{cm}$ high; and 3, with one cylinder replaced by a plastic cube with 6-cm edges. Animal behaviour was recorded with a digital camera and analysed using the EthoVision XT (Noldus) software. The recognition index was calculated using the formula $(\mathrm{Tn}-\mathrm{Tf} / \mathrm{Tn}+\mathrm{Tf}) \times 100 \%$, where $\mathrm{Tn}$ is the duration of new object investigation, and $\mathrm{Tf}$ is the duration of familiar object investigation in the third session of the experiment in accordance with [15].

\section{Morris maze}

Morris maze experiments were performed in a grey circular pool $165 \mathrm{~cm}$ in diameter with $60-\mathrm{cm}$ high walls filled with water to a depth of $40 \mathrm{~cm}$. A round Plexiglas platform, 9 $\mathrm{cm}$ in diameter, was placed in the centre of one of the sectors, $2 \mathrm{~cm}$ below the water level. The pool was kept in a room with many environmental stimuli (stands, calendar, drawers, etc.), the positions of which were constant on the experiment days. The key stimulus above the platform was absent. During the training, animals were placed in the water at four different points, and the time to reach the platform was measured. Once the platform was reached, the animal was left to stay on it for $15 \mathrm{~s}$ and then returned to the home cage for $2 \mathrm{~min}$. The training was performed for 4 days. In a day after training the testing session was performed (study of stability of the formed spatial memory). During the session the animal was placed into the maze without the platform and the time of stay in the "target" quadrant, i.e., in the sector where the platform was before, was estimated for $60 \mathrm{~s}$.

\section{Data analysis}

Statistical treatment of the results was performed using the following nonparametric methods: the Kruskal-Wallis criterion, the median test, and Mann-Whitney-Wilcoxon parameters. The STATISTICA 6.0 (StatSoft, Inc. Tulsa, OK, USA) software package was used.

\section{Results}

\section{Novel object recognition test}

The analysis of the duration of object investigation per acquisition trial (Table 1) did not reveal any statistically significant differences between the groups (Kruskal-Wallis test: $H(9, N=98)=3.88222, p=0.1084)$. Therefore, none of the treatments affected locomotion or orientation and exploratory activity. At the same time, statistically important differences (Kruskal-Wallis test: H (9, N=100)=28.84068, p=0.0007) between the groups were revealed by the object recognition index, characterizing declarative long-term memory associated with perirhinal cortex functions (see Object recognition index line in table 1). A comparison of the individual groups using the Mann-Whitney test revealed a considerable decrease in the index when comparing the control to the sham-operated animals. At the same time, administration of the substances under study led to a significant increase in the index with

Table 1: The effect of the compounds under study on the parameters of orientation and exploratory activities and long-term memory in model of the novel object recognition in rats with the carotid arteries occlusion.

\begin{tabular}{|c|c|c|}
\hline Groups of animals & $\begin{array}{l}\text { Total time of sample exploration } \\
\text { in the exposition session, } s\end{array}$ & Recognition index, \% \\
\hline Sham-operated & $15.7 \pm 2.4$ & $0.65 \pm 0.04$ \\
\hline $\begin{array}{c}\text { Control } \\
\text { (2VO+saline) }\end{array}$ & $15.3 \pm .8$ & $\begin{array}{c}0.18 \pm 0.06 \\
* Z=3.55, p=0.00007\end{array}$ \\
\hline $\begin{array}{c}\mathrm{Am} 250 \\
\left(2 \mathrm{VO}+\mathrm{HLDF}-6-\mathrm{NH}_{2}\right. \\
250 \mu \mathrm{g} / \mathrm{kg})\end{array}$ & $18.4 \pm 1.9$ & $\begin{array}{c}0.60 \pm 0.05 \\
* Z=0.76, p=0.48 \\
\# Z=3.33, p=0.0003\end{array}$ \\
\hline $\begin{array}{c}\mathrm{Am} 50 \\
\left(2 \mathrm{VO}+\mathrm{HLDF}-6-\mathrm{NH}_{2}\right. \\
50 \mu \mathrm{g} / \mathrm{kg})\end{array}$ & $13.8 \pm 1.2$ & $\begin{array}{c}0.52 \pm 0.05 \\
\star Z=1.81, p=0.075 \\
\# Z=2.79, p=0.0035\end{array}$ \\
\hline $\begin{array}{c}\mathrm{Am} 10 \\
\left(2 \mathrm{VO}+\mathrm{HLDF}-6-\mathrm{NH}_{2}\right. \\
10 \mu \mathrm{g} / \mathrm{kg})\end{array}$ & $17.8 \pm 2.2$ & $\begin{array}{c}0.52 \pm 0.13 \\
\star Z=0.53, p=0.63 \\
\# Z=2.79, p=0.0035\end{array}$ \\
\hline $\begin{array}{c}\text { Ac250 } \\
(2 \mathrm{VO}+\mathrm{HLDF}-6-\mathrm{OH} \\
250 \mu \mathrm{g} / \mathrm{kg})\end{array}$ & $16.0 \pm 1.9$ & $\begin{array}{c}0.63 \pm 0.06 \\
\star Z=0.45, p=0.68 \\
\# Z=3.33, p=0.0003\end{array}$ \\
\hline $\begin{array}{c}\text { Ac50 } \\
(2 \mathrm{VO}+\mathrm{HLDF}-6-\mathrm{OH} \\
50 \mu \mathrm{g} / \mathrm{kg})\end{array}$ & $12.7 \pm 0.8$ & $\begin{array}{c}0.61 \pm 0.09 \\
\star Z=0.08, p=0.97 \\
\# Z=2.72, p=0.005\end{array}$ \\
\hline $\begin{array}{c}\text { Ac10 } \\
(2 \mathrm{VO}+\mathrm{HLDF}-6-\mathrm{OH} \\
10 \mu \mathrm{g} / \mathrm{kg})\end{array}$ & $13.4 \pm 0.9$ & $\begin{array}{c}0.53 \pm 0.06 \\
* Z=1.81, p=0.075 \\
\# Z=2.95, p=0.002\end{array}$ \\
\hline $\begin{array}{l}2 \mathrm{VO}+\mathrm{mexidol}, \\
200 \mathrm{mg} / \mathrm{kg}\end{array}$ & $14.4 \pm 1.3$ & $\begin{array}{c}0.5 \pm 0.05 \\
\star Z=1.89, p=0.063 \\
\# Z=2.88, p=0.0028\end{array}$ \\
\hline
\end{tabular}

Am, HLDF-6-NH $\mathrm{N}_{2}$ Ac, HLDF-6-OH. * - in comparison with sham-operated animals, Mann-Whitney criterion. \# - in comparison with comparative to control group,MannWhitney criterion. 
respect to the control, up to the level of values for the shamoperated group, except for the HLDF-6- $\mathrm{NH}_{2}$ peptide at doses of $50 \mu \mathrm{g} / \mathrm{kg}$ and $10 \mu \mathrm{g} / \mathrm{kg}$ and the HLDF-6-OH peptide at dose of $10 \mu \mathrm{g} / \mathrm{kg}$ and the reference drug mexidol. However, in these groups the recognition index was essentially higher than in the control experiment. These data suggest a U-shaped doseresponse curve for the HLDF-6- $\mathrm{NH}_{2}$ peptide in this model, as was demonstrated by [12] in the AD model.

\section{Long-term spatial conditioned memory inthe Morris maze}

The main characteristic of long-term spatial conditioned memory in this model is the time to reach the platform in the first attempt on each of the training days. An analysis did not reveal any statistically significant differences between the groups by this value on the first (Kruskal-Wallis test: $\mathrm{H}$ $(9, N=100)=11.67372, p=0.2323)$ or second (Kruskal-Wallis test: $H(9, N=100)=13.90251, p=0.1258)$ training day. At the same time, statistically significant intergroup differences were revealed on training days 3 (Kruskal-Wallis test: H (9, $\mathrm{N}=100$ ) $=17.39247, \mathrm{p}=0.0429$ ) and 4 (Kruskal-Wallis test: $\mathrm{H}$ $(9, N=100)=24.35808, p=0.0038)$. Analysis using the MannWhitney test revealed a statistically significant increase in the time to reach the platform on training days 3 and 4 in the control rats compared to the values for the sham-operated rats, which demonstrates the disturbance of the long-term spatial memory due to occlusion of the carotid arteries (Table 2).

The HLDF-6- $\mathrm{NH}_{2}$ peptide at a dose of $250 \mu \mathrm{g} / \mathrm{kg}$ restored the characteristics of the long-term memory on training days 3 and 4 up to the level of values for the sham-operated group; however, the effect of this peptide at doses of 50 and $10 \mu \mathrm{g} / \mathrm{kg}$ was observed only on day 4 and was very mild. The stimulatory effect of the HLDF-6-OH peptide on the formation of long-term memory became apparent only at doses of 250 $\mu \mathrm{g} / \mathrm{kg}$ and $50 \mu \mathrm{g} / \mathrm{kg}$; this effect was observed only on day 4 of the experiment and was weaker than the effect for the HLDF$6-\mathrm{NH}_{2}$ peptide. The HLDF-6-OH peptide at a dose of $10 \mu \mathrm{g} / \mathrm{kg}$ was not effective. The reference drug mexidol was not effective on either day 3 or 4 of the experiment. Significant intergroup differences were also observed for the index of stability of the formed spatial memory, i.e., the time of stay in the target quadrant during the test without the platform (KruskalWallis test: $\mathrm{H}(9, \mathrm{~N}=100)=29.61716, \mathrm{p}=0.0005)$ (Figure 1). A comparison of the individual groups revealed that the HLDF$6-\mathrm{NH}_{2}$ peptide at a dose of $250 \mu \mathrm{g} / \mathrm{kg}$ enhanced the stability of

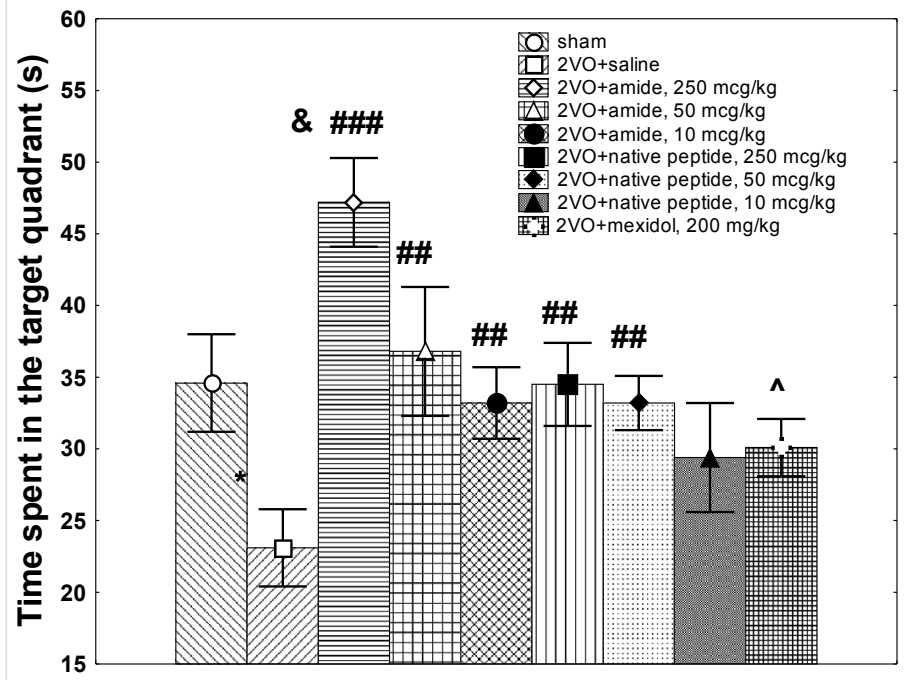

Figure 1: The effect of the compounds under study on the parameters of stability of the spatial memory formed in the Morris maze tests in rats with the carotid arteries occlusion.

Table 2: The effect of compounds under study on the parameters of long-term spatial contextual memory during training of rats with the carotid arteries occlusion in the Morris maze.

\begin{tabular}{|c|c|c|c|c|}
\hline \multirow{2}{*}{ Groups of animals } & \multicolumn{4}{|c|}{ Time to reach the platform in the first attempt, $s$} \\
\hline & on day 1 of training & on day 2 of training & on day 3 of training & on day 4 of training \\
\hline Sham-operated & $58.6 \pm 1.0$ & $56.0 \pm 3.2$ & $28.1 \pm 5.6$ & $31.1 \pm 5.6$ \\
\hline $\begin{array}{c}\text { Control } \\
\text { (2VO+saline) }\end{array}$ & $58.8 \pm 0.81$ & $52.1 \pm 2.9$ & $\begin{array}{c}48.1 \pm 4.7 \\
\star Z=2.29, p=0.023\end{array}$ & $\begin{array}{c}50.4 \pm 3.6 \\
\star Z=2.48, p=0.011\end{array}$ \\
\hline $\begin{array}{c}\mathrm{Am} 250 \\
\left(2 \mathrm{VO}+\mathrm{HLDF}-6-\mathrm{NH}_{2}\right. \\
250 \mu \mathrm{g} / \mathrm{kg})\end{array}$ & $60.0 \pm 0.00$ & $50.6 \pm 3.9$ & $\begin{array}{c}37.0 \pm 6.3 \\
\star Z=1.10, p=0.22 \\
\# Z=1.20, p=0.25\end{array}$ & $\begin{array}{c}32.2 \pm 5.7 \\
\star Z=0.28 . p=0.85 \\
\# Z=2.22 . p=0.029\end{array}$ \\
\hline $\begin{array}{c}A m 50 \\
\left(2 \mathrm{VO}+\mathrm{HLDF}-6-\mathrm{NH}_{2}\right. \\
50 \mu \mathrm{g} / \mathrm{kg})\end{array}$ & $56.1 \pm 2.20$ & $56.6 \pm 1.7$ & $\begin{array}{c}45.5 \pm 5.2 \\
\star Z=2.13, p=0.035 \\
\# Z=0.43, p=0.68\end{array}$ & $\begin{array}{c}44.2 \pm 4.7 \\
\star Z=1.48 . p=0.14 \\
\# Z=0.93 .=0.39\end{array}$ \\
\hline $\begin{array}{c}\mathrm{Am} 10 \\
\left(2 \mathrm{VO}+\mathrm{HLDF}-6-\mathrm{NH}_{2}\right. \\
10 \mu \mathrm{g} / \mathrm{kg})\end{array}$ & $60.0 \pm 0.00$ & $51.6 \pm 5.1$ & $\begin{array}{c}49.6 \pm 3.4 \\
\star Z=2.39, p=0.015 \\
\# Z=0.31, p=0.8\end{array}$ & $\begin{array}{c}45.1 \pm 3.9 \\
\star Z=1.84 . p=0.052 \\
\# Z=0.93 . p=0.39\end{array}$ \\
\hline $\begin{array}{c}\text { Ac250 } \\
\text { (2VO+HLDF-6-OH. } 250 \mu \mathrm{g} / \mathrm{kg})\end{array}$ & $59.3 \pm 0.6$ & $58.7 \pm 0.7$ & $\begin{array}{c}51.2 \pm 5.2 \\
\star Z=2.25, p=0.023 \\
\# Z=0.78, p=0.48\end{array}$ & $\begin{array}{c}38.4 \pm 6.2 \\
* Z=0.307 . p=0.31 \\
\# Z=1.47 . p=0.17\end{array}$ \\
\hline $\begin{array}{c}\text { Ac50 } \\
\text { (2VO+HLDF-6-OH. } 50 \mu \mathrm{g} / \mathrm{kg})\end{array}$ & $53.8 \pm 3.3$ & $56.4 \pm 1.9$ & $\begin{array}{c}46.2 \pm 3.7 \\
\star Z=2.57, p=0.009 \\
\# Z=0.92, p=0.39\end{array}$ & $\begin{array}{c}33.3 \pm 4.6 \\
* Z=2.58 . p=0.009 \\
\# Z=0.26 . p=0.8\end{array}$ \\
\hline $\begin{array}{c}\text { Ac10 } \\
\text { (2VO+HLDF-6-OH. } 10 \mu \mathrm{g} / \mathrm{kg})\end{array}$ & $53.2 \pm 4.9$ & $47.9 \pm 6.0$ & $\begin{array}{c}53.3 \pm 3.8 \\
Z=2.91 \cdot p=0.002 \\
\# Z=1.19 . p=0.31\end{array}$ & $\begin{array}{c}56.4 \pm 2.2 \\
Z=3.13 . p=0.0007 \\
\# Z=1.49 . p=0.19\end{array}$ \\
\hline $2 \mathrm{VO}+$ mexidol $200 \mathrm{mg} / \mathrm{kg}$ & $55.2 \pm 2.9$ & $48.5 \pm 2.5$ & $\begin{array}{c}46.1 \pm 3.7 \\
\star Z=2.57 . p=0.009 \\
\# Z=0.89 . p=0.39\end{array}$ & $\begin{array}{c}47.9 \pm 3.6 \\
\star Z=2.08 . p=0.035 \\
\# Z=0.39 . p=0.63\end{array}$ \\
\hline
\end{tabular}


spatial memory not only against the control group value but also against the value seen in sham-operated animals. Doses of 50 and $10 \mu \mathrm{g} / \mathrm{kg}$ were also effective and enhanced the stability of spatial memory up to the level of sham-operated rats. The HLDF-6-OH peptide at doses of 250 and $50 \mu \mathrm{g} / \mathrm{kg}$ was effective, but the efficiency was considerably lower than theHLDF-6- $\mathrm{NH}_{2}$ peptide, and at the dose of $10 \mu \mathrm{g} / \mathrm{kg}$, the effect of HLDF-6-OH peptide was low-grade. The group receiving mexidol was similar to the control.

\section{Discussion}

Cerebrovascular disturbances are among the major causes of death and disability worldwide. Identification of effective neuroprotective and nootropic agents preventing the development of amnesia under these conditions is one of most urgent tasks of modern science. Neuroprotectors are implied to promote/support eradication of neurotoxic compounds (glutamate, free radicals, and transmembrane calcium) from damaged areas of the brain, improve metabolism in neurons, and stabilize the neuron membrane charge. The insufficient effects of the current neuroprotective drugs are thought to originate in the fact that they have been designed to protect neurons only. However, stroke is not merely a process of neuron damage; it is a whole-brain disease, involving disruption of normal functional links and relationships. This is why the search for more efficient neuroprotectors that can influence various structures of the brain together with major therapy methods is ongoing. Earlier, the neuroprotective effect of the HLDF-6-OH peptide (acidic form) was demonstrated under conditions of tissue hypoxia of Purkinje cells in the cerebellum upon direct application to the tissue in vivo as well as under conditions of cerebral hypoperfusion (bilateral occlusion of common carotid arteries, which is called 2-vessel occlusion, or 2-VO, model) upon intraperitoneal administration $[7,16]$. In the 2-VO model, it was revealed that the acid form of HLDF6 not only alleviates memory impairment, but also significantly increases the level of $\mathrm{N}$-acetylaspartate and $\mathrm{N}$-acetylaspartate / creatine ratio in ischemic animals [11]. Here, we compare the neuroprotective and nootropicactivities of two pharmaceutical substances, the HLDF-6 peptide (HLDF-6-OH) and its amide form, HLDF-6- $\mathrm{NH}_{2}$, upon intranasal administration in an animal model of a cerebrovascular pathology, ischaemic stroke (chronic occlusion of carotid arteries, 2-VO model). To evaluate cognitive functions in animals, two tests were used: the novel object recognition test, allowing for evaluation of declarative long-term memory, and the Morris maze, allowing for evaluation of long-term spatial conditioned memory.

A comparative analysis of the data obtained demonstrated that the neuroprotective activity of HLDF-6- $\mathrm{NH}_{2}$ in the IS model, evaluated by improvement of cognitive functions in animals, surpassed that of the native HLDF-6-OH peptide. Similar data were obtained by [12] in animal models of AD. The difference between the studied pharmaceutical substances' effects was particularly pronounced in the long- term spatial conditioned memory in the Morris maze for both the IS and BA models. When compared with the reference neuroprotector agents, the HLDF- 6 amide performed better in efficient dosage parameters and biological activity. The peptide protected rats upon carotid artery occlusion much more efficiently than mexidol, a drug frequently used in stroke therapy, at a dose 800-fold lower than that of mexidol. In addition, in contrast to mexidol, which damages the liver and kidneys, the amide form of HLDF- 6 was not toxic based on the data obtained in preclinical studies [17]. Taken together, the data obtained allow for the conclusion that the HLDF6- $\mathrm{NH}_{2}$ peptide reactivates efficiently impaired cognitive functions in all models under study, both IS and AD. A dose of $250 \mu \mathrm{g} / \mathrm{kg}$ resulted in practically complete restoration of the functions (statistically significant differences compared with the control and no differences with sham-operated animals or exceeding the latter values). Notably, in some cases, animals receiving the HLDF-6- $\mathrm{NH}_{2}$ peptide at the dose $250 \mu \mathrm{g} / \mathrm{kg}$ even surpassed the values of sham-operated animals. Thus, the efficiency of spatial memory of experimental animals in the IS model surpasses the corresponding value of sham-operated animals by $40 \%$. Therefore, a dose of $250 \mu \mathrm{g} / \mathrm{kg}$ HLDF- $6-\mathrm{NH}_{2}$ peptide was chosen as the subject for further preclinical and clinical studies and was established as an efficient therapeutic dose.

\section{Conclusion}

The HLDF- 6 peptide is a fragment of natural human leukaemia differentiation factor (HLDF) present in the blood and central nervous system of mammals and humans. Preclinical studies of the HLDF-6- $\mathrm{NH}_{2}$ peptide demonstrated that the therapeutic agent based on the substance is soluble and easily metabolized; it exhibits no immunogenicity and is characterized by high efficiency. Finally, it is not toxic and safe at a dose equivalent to a 10 -fold therapeutic dose for humans [17]. The results of preclinical studies with this agent provide a positive outlook for further clinical investigation. In view of the high demand for the agent and if clinical trials are successful, it will surely become widely used in clinical practice to treat IS and AD. We developed a drug based on the HLDF-6 peptide that belongs to a new class of drugs, i.e., the peptide neuroprotectors. We were the first to discover the HLDF protein and HLDF-6 peptide and are still the only group to work with these compounds. These are original results and are the first of their kind. None of the currently used peptidebased drugs have structural homology with the HLDF-6 peptide. The advantages of pharmaceutical substance based on the HLDF- 6 amide over other existing drugs include the following: originality, distinct manifestation of the therapeutic effect, high level and wide range of combined nootropic and neuroprotector activities (efficient in treatment of both IS and $\mathrm{AD}$ ), high efficiency at low and extra-low doses, the absence of adverse effects, lack of toxicity, and efficient administration route (intranasal administration). 


\section{References}

1. Feigin VL, Forouzanfar $\mathrm{MH}$, Krishnamurthi R, Mensah GA, Connor $M$ et al. Global and regional burden of stroke during 1990-2010: findings from the Global Burden of Disease Study. Lancet. 2010; 383: 245-255. PubMed: https://www.ncbi.nlm.nih.gov/pubmed/24449944

2. Rybnikov VYu, Zakutsky NG. Peptide regulation of the brain functions. Stela. Sankt-Petersburg. Russia. 2000.

3. Koroleva SV, Ashmarin IP. Development and application of an expert system for analysis of the functional continuum of regulatory peptides. Russ J Bioorg Chem. 2006; 32: 224-230. PubMed: https://www.ncbi. nlm.nih.gov/pubmed/16808167

4. Kostanyan IA, Astapova MV, Starovoytova EV, Dranitsyna SM, Lipkin VM. A new human leukemia cell $8.2 \mathrm{kDa}$ differentiation factor: Isolation and primary structure determination. FEBS Lett. 1994; 356: 327-329. PubMed: https://www.ncbi.nlm.nih.gov/pubmed/7805865

5. Kostanyan IA, Astapova MV, Navolotskaya EV, Lepikhova TN, Dranitsyna $\mathrm{SM}$, et al. A biologically active fragment of the differentiation factor of the HL-60 line cells: Identification and properties. Russ J Bioorg Chem. 2000; 26: 450-456. PubMed: https://www.ncbi.nlm.nih.gov/ pubmed/11008640

6. Sakharova N Yu, Kostanyan IA, Lepikhova TN, Lephihov KA Navolotskaya EV, et al. Effects of synthetic peptides TQVEHR and NGENHR on early mouse embryo development in vitro. Doklady Biochemistry. 2000; 372: 84-86. PubMed: https://www.ncbi.nlm.nih. gov/pubmed/10935171

7. Rzhevsky DI, Zhokhov SS, Babichenko II, Goleva AV, Goncharenko EN.et al. HLDF-6 peptide affects behavioral reactions and organism functions dependent on androgen hormones in normal and castrated male mice. Regulatory Peptides. 2005; 127: 111-121. PubMed: https:// www.ncbi.nlm.nih.gov/pubmed/15680477

8. Kostanyan IA, Zhokhov SS, Storozheva ZI, Proshin AT, Surina EA, et al. Neuroprotective effect of the hexapeptide HLDF- 6 on rat hippocampal neurons on the in vivo and in vitro models of Alzheimer's disease. Russ J Bioorg Chem. 2006; 32: 360-367.

9. Sewell RD, Gruden MA, Pache DM, Storozheva ZI, Kostanyan IA, et al. Does the human leukaemia differentiation factor fragment HLDF6 improve memory via brain DNA and protein synthesis? J.
Psychopharmacol. 2005; 19: 602-608. PubMed: https://www.ncbi.nlm. nih.gov/pubmed/16272181

10. Storozheva ZI, Proshin AT, Zhokhov SS, Sherstnev VV, Rodionov IL, et al. Hexapeptides HLDF-6 and PEDF-6 restore memory in rats after chronic intracerebroventricular treatment with beta-amyloid peptide a beta (25-35). B Exp Biol Med. 2006; 141: 319-322. PubMed: https:// www.ncbi.nlm.nih.gov/pubmed/17073149

11. Kostanyan IA, Storozheva ZI, Semenova NA, Lipkin VM. Postischemic administration of HLDF-6 peptide ameliorates cognitive dysfunction and brain damage induced by chronic cerebral Ischemia in rats. Doklady Biological Sciences. 2009; 428: 418-422. PubMed: https:// www.ncbi.nlm.nih.gov/pubmed/19994779

12. Bogachouk AP, Storozheva ZI, Solovjeva OA, Sherstnev VV, Zolotarev Yu A, et al. Comparative study of the neuroprotective and nootropic activities of the carboxylate and amide forms of the HLDF- 6 peptide in animal models of Alzheimer's disease. J Psychopharmacol. 2016; 30 : 978-921. PubMed: https://www.ncbi.nlm.nih.gov/pubmed/26628555

13. Mironov AN, Bunyatyan ND, Vasiljeva AN, Verstakova OL, Zhuravleva $\mathrm{MV}$,et al. Manual for preclinical trials of medicinal agents. Part 1. Moscow: Grif and Co. 2012

14. Choi BR, Kwon KJ, Park SH, Jeon WK, Han SH, et al. Alternations of Septal-hippocampal System in the Adult Wistar Rat with Spatial Memory Impairments Induced by Chronic Cerebral Hypoperfusion. Exp Neurobiol. 2011; 20: 92-99. PubMed: https://www.ncbi.nlm.nih.gov/ pubmed/22110366

15. Cechetti F, Pagnussat AS, Worm PV, Elsner VR, Ben Jda Costa, et al Chronic brain hypoperfusion causes early glial activation and neuronal death and subsequent long-term memory impairment. Brain Res. Bull. 2012; 87: 109-116. PubMed: https://www.ncbi.nlm.nih.gov/ pubmed/22040859

16. Zhokhov SS, Kostanyan IA, Gibanova NV, Surina EA, Rodionov IL, et al. Different mechanisms of protective and differentiative activities of homological peptides TGENHR and TQVEHR. BiochemistryMoscow. 2004; 69: 861-869. PubMed: https://www.ncbi.nlm.nih.gov/ pubmed/15377265

17. Rzhevskiy DI, Kravchenko IN, Sadovnikova ES, Rasskazova EA Novikova NI, et al. Preclinical trials of safety of the nootropic remedy on the base of amide form of the fragment of leukocytes differetntiation factor. Biopharmaceutical Journal. 2017; 9: 50-56. 